\title{
Inquérito sorológico para a infecção por Toxoplasma gondii em ameníndios isolados, Mato Grosso
}

\author{
Serological survey of Tox oplasma gondii infection \\ in isolated Amerindians, Mato Grosso

\begin{abstract}
Maria Regina Reis Amendoeira' ${ }^{1}$, Cleide Aparecida Queiroz Sobral' ${ }^{1}$, Antonio Teva ${ }^{2}$,
\end{abstract} \\ Josué Nazareno de Lima ${ }^{3}$ e Carlos Henrique Klein ${ }^{4}$
}

\begin{abstract}
Resumo Este estudo determinou a ocorrência de anticorpos anti-Toxoplasma gondii em população indígena do Mato Grosso, os Enawenê-Nawê. Estes habitam uma vasta região selvagem, com raros contatos com nãoíndios. Não apresentam animais domésticos, inclusive gatos. A dieta é baseada em insetos, mandioca, milho, mel e fungos e não se alimentam de carne, exceto de peixe. Com base no exposto, desenvolveu-se análise sorológica, por meio de ELISA - IgG e IFI - IgG e IgM. De 148 soros, 80,4\% foram ELISA ou IFI- IgG positivos. Não foram detectados casos de lgM reagentes. Nesse grupo as taxas de soropositividade aumentaram significativamente com a idade, de $50 \%$ a $95 \%$. Analisando-se os hábitos e costumes, aliados à alta soropositividade encontrada, sugere-se que a presença de felinos silvestres nas imediações da aldeia e coleções de água poderia ter papel importante como fonte de infecção, contaminando o solo e, conseqüentemente, os insetos e fungos consumidos pelos índios.
\end{abstract}

Palavras-chaves: Populações indígenas. Epidemiologia. Toxoplasmose.

Abstract This study determined the occurrence of the antibodies anti-Toxoplasma gondii among the EnawenêNawê, an indigenous population of Mato Grosso. These inhabit a vast wild area, with rare contacts with nonIndians. They do not keep domestic animals, including cats. Their diet is based on insects, cassava, corn, honey and mushrooms, they do not consume meat, except fish. Based on the above, serologic tests ELISA$\lg G$ and indirect fluorescent antibody test for $\mathrm{lg}$ G/lgM were performed. From 148 samples, $80.4 \%$ positive for IgG by ELISA or indirect fluorescent antibody test. No IgM reagent cases were detected. In that group the seropositivity rates increased significantly with age from 50\% to 95\%. Having analyzed their customs and habits, together with the high seropositivity found, it is suggested that the presence of wild felines in the vicinity of the village and areas where water collects could play an important role as an infection source, contaminating soil and consequently insects and mushrooms consumed by the Indians.

Key-words: Indigenous populations. Epidemiology. Toxoplasmosis.

A toxoplasmose é uma zoonose de ampla distribuição geográfica, sendo encontrada em todos os continentes dos mais variados climas ${ }^{20}$. A variabilidade da freqüência da infecção está ligada a diversos fatores, tais como: padrões culturais da população, hábitos alimentares, faixa etária, e procedência urbana ou rural ${ }^{7}$.

A grande dispersão do parasita pode ser determinada pela possibilidade deste apresentar vários mecanismos de transmissão: ingestão de cistos presentes em carnes cruas ou mal cozidas, ingestão de oocistos presentes em fezes de felídeos que contaminam alimentos e água, manipulação de terra contaminada com oocistos, entre outros ${ }^{12}$. Estes fatores podem ser as causas das altas prevalências de anticorpos para Toxoplasma gondii em grupos humanos com hábitos, costumes e etnias bem diferentes, sendo dependentes do grau e da freqüência de exposição aos referidos fatores ${ }^{11}$.

\footnotetext{
1. Departamento de Protozoologia do Instituto Oswaldo Cruz da Fundação Oswaldo Cruz, Rio de Janeiro, RJ. 2.Departamento de Imunologia do Instituto Oswaldo Cruz da Fundação Oswaldo Cruz, Rio de Janeiro, RJ. 3.Unidade de Diagnóstico Assistência e Tratamento do Programa Nacional de Doenças Sexualmente Transmissíveis e AIDS do Ministério da Saúde, Brasília, DF. 4.Departamento de Epidemiologia da Escola Nacional de Saúde Pública da Fundação Oswaldo Cruz, Rio de Janeiro, RJ.

Endereço para correspondência: Dra Maria Regina Reis Amendoeira. Dept ${ }^{\circ}$ de Protozoologia/FIOCRUZ. Av. Brasil 4365, Pavilhão Arthur Neiva, sala 1B, 21045-900 Rio de Janeiro, RJ, Brasil.

Tel: 5521 2598-4336/4337 Ramal 122. Fax: 5521 2280-5449/2598-4220

e-mail: amendoeira@fiocruz.br

Recebido para publicação em 21/10/02

Aceito em 12/9/2003
} 
Em estudos com índios brasileiros têm-se encontrado ocorrência da infecção variando de 39\% a 100\% 410141518 . Entretanto, Wallace et al, utilizando a reação de Sabin-Feldman (RSF), verificaram prevalências inferiores a $2 \%$ em populações primitivas de Nova Guiné, onde a presença de gatos e felídeos silvestres é pouco freqüente, em contraposição às prevalências de 14 a $34 \%$ em populações que vivem onde os gatos são numerosos ou antigos na área ${ }^{23}$.
Os mesmos autores observaram uma prevalência de $50 \%$ em indígenas primitivos das selvas da Colômbia que não possuíam gatos domésticos, mas se alimentavam de felídeos silvestres.

O propósito desse estudo foi determinar a ocorrência da infecção por $T$. gondii em uma população vivendo isolada, com hábitos e costumes preservados, considerando os fatores de risco ambientais.

\section{MATERIAL E MÉTODOS}

População estudada. A população EnawenêNawê, encontra-se em uma área indígena com 750. 000 hectares de extensão, na região noroeste do Estado do Mato Grosso (Figura 1) ${ }^{16}$. No território Enawenê-
Nawê encontram-se altitudes que variam de 200 a 500 metros, com pluviosidade entre 1.500 a $2.500 \mathrm{~mm}$ sendo que a umidade relativa do ar atinge $80 \%$.

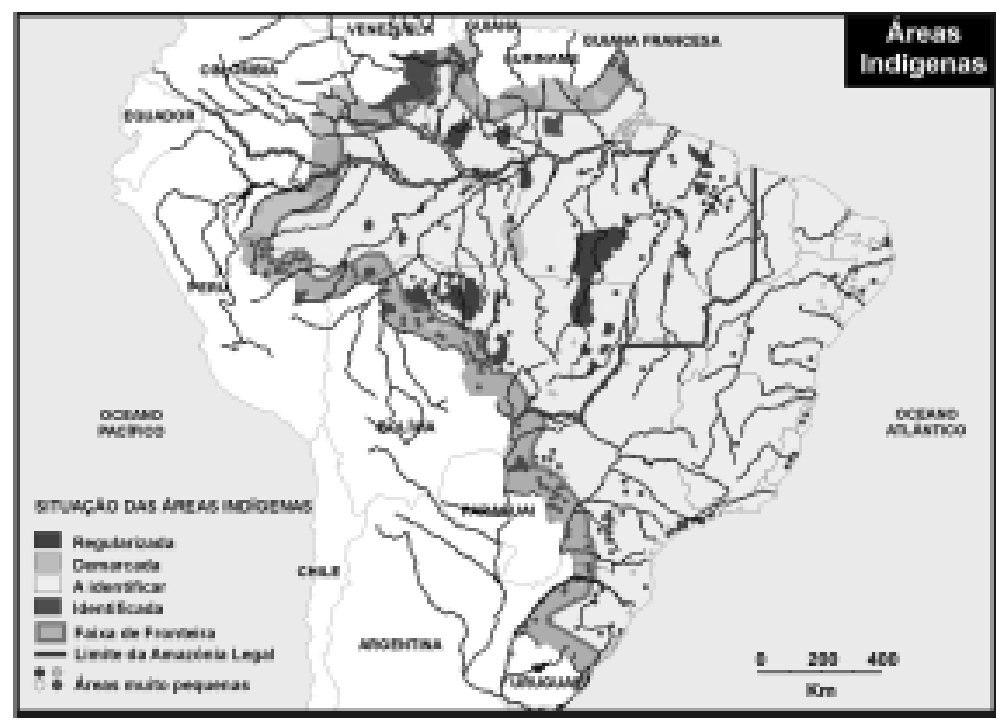

Figura 1 - Mapa do Brasil com a localização de áreas indígenas, com destaque a etnia Enawenê-Nawê.

Muito possivelmente, as primeiras notícias que se têm dos Enawenê-Nawê foram fornecidas pelos Waimaré (Paresi) a Cândido Mariano da Silva Rondon, quando, em 1909, a Comissão de Linhas telegráficas, por ele dirigida, atravessou o Noroeste do Mato Grosso do alto rio Juruena. Porém, o primeiro contato pacífico se deu em 1974 e a população naquele momento era de 97 pessoas, morando em sete casas comunais. Já em 1995, esta população contava com 245 indivíduos, enquanto que a informação mais recente é de 320 pessoas ${ }^{17}$. Os índios vivem da pesca, cultivam milho, mandioca e leguminosas. Também são consumidos frutos silvestres, coletados em épocas específicas do $a n 0^{16}$.

Estes indígenas não consomem carne vermelha, alimentam-se de insetos, como larvas e pupas de coleópteros e lepidópteros, cupins, formigas, sendo estas coletadas unicamente pelas mulheres, particularmente pelas crianças do sexo feminino. Larvas e pupas de vespas são coletadas pelos homens. O mel, outro produto de grande importância na alimentação desse grupo, é coletado somente pelos homens ${ }^{16}$. Fungos também fazem parte da alimentação, sendo encontrados mais freqüentemente no ambiente das matas ciliares, por serem esses locais mais úmidos e com maior concentração de matéria orgânica. Sua coleta é realizada pelas mulheres e crianças. Esses fungos são consumidos in natura ou após sofrerem processo de fervura em água ${ }^{16}$.

A aldeia onde vivem os Enawenê-Nawê apresenta configuração circular, contendo dez casas comunais retangulares, dispostas no sentido radial, e uma casa em seu interior, não exatamente no centro. A casa cerimonial apresenta forma circular, muito diferente das casas comunais, como está representado na Figura $2^{16}$. 


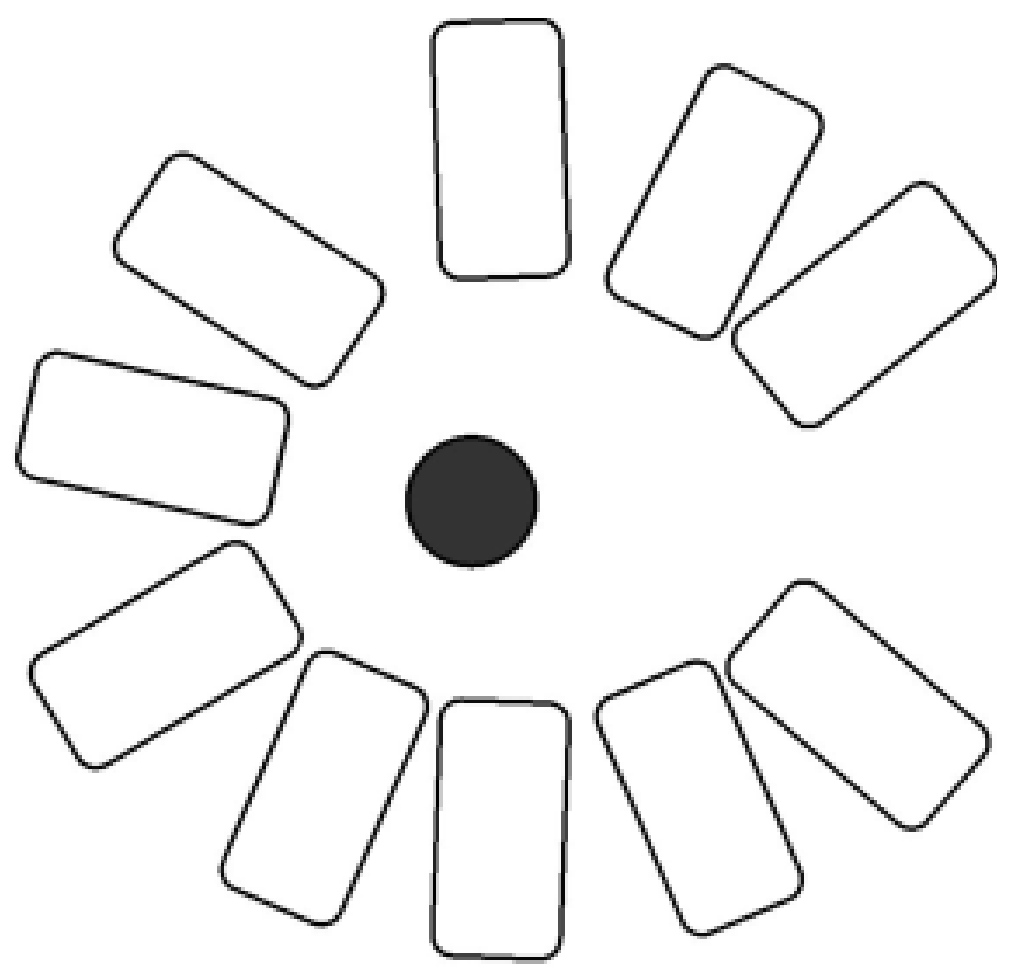

Figura 2 - Croqui da Aldeia Enawenê-Nawê com casas comunais (retângulos) e uma casa cerimonial (círculo preenchido).

Os indivíduos mantêm contato freqüente com o solo e a água dos rios, não possuem animais domésticos, mas há animais silvestres, incluindo felinos, nas imediações da aldeia e coleções de água. A população vive praticamente isolada sem contato direto com o não- índio, isso somente ocorrendo quando equipes médicas e da FUNAl vão até a região ${ }^{16}$.

Coleta das amostras. O presente trabalho foi realizado a partir da análise de soros de 148 índios, representando $60,4 \%(n=245)$ da população total dos Enawenê-Nawê. A amostra incluía homens, mulheres e crianças de $6-76$ anos de idade. A equipe responsável pelo projeto de saúde OPAN/NESPI-
FIOCRUZ População Indígena: Enawenê-Nawê realizou a coleta de sangue, inicialmente para um inquérito de arboviroses.

Métodos sorológicos. Foram utilizados ELISA (Enzyme - Linked Immunosorbent Assay) para pesquisa de anticorpos IgG anti-Toxoplasma gondii ${ }^{22}$ e IFI (Imunofluorescência Indireta) para pesquisa de anticorpos IgM e IgG específicos ${ }^{5}$.

Análise estatística. $O$ teste de $\chi^{2}$ foi realizado para as variáveis como sexo e idade com relação à soropositividade. Um valor de $p<0,05$ foi considerado significante. Também foi utilizado um teste nãoparamétrico de tendência em grupos ordenados ${ }^{21}$.

\section{RESULTADOS}

Observou-se soropositividade de $80,4 \%$ para anticorpos IgG na população, quando se analisaram os resultados positivos para ELISA ou IFI. Na pesquisa para anticorpos IFI-IgM, não foi encontrado nenhum indivíduo com sorologia positiva.

Para garantir a segurança do diagnóstico, foram utilizados os dois métodos sorológicos, pois havia discordância em $12(8,1 \%)$ soros reagentes com ELISA e não reagentes para o teste de IFI; em contrapartida, foram encontrados três (2\%) soropositivos com IFI que foram negativos em ELISA.
$\mathrm{Na}$ Tabela 1, estão apresentados os percentuais de IgG reagentes segundo o sexo e a idade agrupada. Encontrou-se positividade de $75,9 \%$ e $86,1 \%$, entre os indivíduos do sexo feminino e do sexo masculino, respectivamente. Não houve diferença significativa de positividade de $\lg$ reagentes entre os $\operatorname{sexos}\left(\chi^{2}=2,43\right.$; $p=0,119$ ). Observou-se crescimento de soropositividade até a terceira década de vida, estabilizando-se em percentuais bem altos, a partir daí, tanto nos homens como nas mulheres. O menor índice de soropositividade ocorreu nos mais jovens, aqueles com menos de 10 anos. Observou-se heterogeneidade significativa nas 
positividades entre os grupos etários $\left(\chi^{2}=15,61\right.$; $p=0,008$ ), assim como uma tendência significativa de aumento das positividades nos grupos etários mais avançados ( $z=3,49 ; p=0,00)$.

O título mais freqüente de anticorpos foi de 1:64, utilizando-se IFI, como se pode ver na Tabela 2. Esta observação é especialmente notável nos maiores de 20 anos.

Apenas um indivíduo do sexo masculino, com 16 anos de idade, apresentou título de 1:4096, não incluído na Tabela 2.

Tabela 1 - Percentual de IgG reagentes (ELISA ou IFI) e respectivo número total de índios observados em cada grupo, nos Enawenê-Nawê (Mato Grosso), segundo sexo e idade.

\begin{tabular}{|c|c|c|c|c|c|c|c|c|c|c|c|c|c|c|}
\hline \multirow[b]{3}{*}{ Sexo } & \multicolumn{14}{|c|}{ Idade agrupada em anos } \\
\hline & \multicolumn{2}{|c|}{$6-9$} & \multicolumn{2}{|c|}{$10-19$} & \multicolumn{2}{|c|}{$20-29$} & \multicolumn{2}{|c|}{$30-39$} & \multicolumn{2}{|c|}{$40-49$} & \multicolumn{2}{|c|}{$\geq 50$} & \multicolumn{2}{|c|}{ Total } \\
\hline & $\%$ & $\mathrm{n}^{\circ}$ & $\%$ & $\mathrm{n}^{\circ}$ & $\%$ & $\mathrm{n}^{\circ}$ & $\%$ & $\mathrm{n}^{\circ}$ & $\%$ & $\mathrm{n}^{\circ}$ & $\%$ & $\mathrm{n}^{\circ}$ & $\%$ & $\mathrm{n}^{\circ}$ \\
\hline Feminino & 42,9 & 7 & 64,3 & 28 & 82,4 & 17 & 86,7 & 15 & 83,3 & 6 & 100,0 & 10 & 75,9 & 83 \\
\hline Masculino & 60,0 & 5 & 80,0 & 25 & 90,0 & 10 & 100,0 & 11 & 100,0 & 4 & 90,0 & 10 & 86,1 & 65 \\
\hline Total & 50,0 & 12 & 71,7 & 53 & 85,1 & 27 & 92,3 & 26 & 90,0 & 10 & 95,0 & 20 & 80,4 & 148 \\
\hline
\end{tabular}

\begin{tabular}{|c|c|c|c|c|c|c|c|c|c|c|c|c|}
\hline \multirow{3}{*}{ IFI } & \multicolumn{12}{|c|}{ Idade agrupada em anos } \\
\hline & \multicolumn{2}{|c|}{$6-9$} & \multicolumn{2}{|c|}{$10-19$} & \multicolumn{2}{|c|}{$20-29$} & \multicolumn{2}{|c|}{$30-39$} & \multicolumn{2}{|c|}{$\geq 40$} & \multicolumn{2}{|c|}{ Total } \\
\hline & $\%$ & $\mathrm{n}^{\circ}$ & $\%$ & $\mathrm{n}^{\circ}$ & $\%$ & $\mathrm{n}^{\circ}$ & $\%$ & $\mathrm{n}^{\circ}$ & $\%$ & $\mathrm{n}^{\circ}$ & $\%$ & $\mathrm{n}^{\circ}$ \\
\hline 1: 16 & - & - & 33,3 & 10 & 27,3 & 6 & 20,8 & 5 & 7,7 & 2 & 21,7 & 23 \\
\hline 1: 64 & 25,0 & 1 & 33,3 & 10 & 31,8 & 7 & 50,0 & 12 & 50,0 & 13 & 40,6 & 43 \\
\hline 1: 256 & 25,0 & 1 & 26,7 & 8 & 27,3 & 6 & 20,8 & 5 & 34,6 & 9 & 27,3 & 29 \\
\hline $1: 1024$ & 50,0 & 2 & 6,7 & 2 & 13,6 & 3 & 8,3 & 2 & 7,7 & 2 & 10,4 & 11 \\
\hline Total & 100,0 & 4 & 100,0 & 30 & 100,0 & 22 & 100,0 & 24 & 100,0 & 26 & 100,0 & 106 \\
\hline
\end{tabular}

\section{DISCUSSÃO}

A alta ocorrência de anticorpos anti-T. gondii nos silvícolas em estudo $(80,4 \%)$, com hábitos e costumes praticamente preservados, foi semelhante à demonstrada pelo grupo indígena Kren-Akore, com $88,6 \%$ de soropositividade, o qual tinha mantido o primeiro contato com o não-índio dois anos antes do momento daquele estudo $^{13}$, e em ameríndios de etnia Guajiba, da selva amazônica na Venezuela, com $88 \%$ de soropositividade ${ }^{19}$. Entretanto, em outras populações indígenas não tão isoladas, foram detectadas taxas mais baixas: $52 \% 4$; $64,8 \%{ }^{10} ; 56,2 \%$ a $70,8 \%{ }^{9} ; 51 \%^{18}$.

A alta prevalência encontrada no grupo dos Enawenê-Nawê é difícil de ser justificada pelos mecanismos de transmissão mais comuns, como ingestão de cistos contidos em carne crua ou mal cozida e ingestão de oocistos eliminados com as fezes de felídeos, que podem contaminar água, solo e alimentos crus, uma vez que estes índios não comem carne, exceto peixe, que até o presente momento não foi identificado como hospedeiro intermediário, e não possuem gatos. A existência de felídeos silvestres, em baixa densidade e grande dispersão na região, não seria suficiente para causar um nível de contaminação do solo a ponto de justificar a alta ocorrência de soropositividade encontrada na população indígena Enawenê-Nawê. Uma explicação possível para este fato seria uma maior concentração destes felídeos nas coleções de águas, também freqüentadas pelos índios.
Alguns autores atribuem grande importância ao consumo de carne vermelha em relação ao aumento da soropositividade ${ }^{1} 1^{11}{ }^{12}$. Este fato é corroborado por um estudo realizado com índios Ticuna, onde as taxas de prevalência de títulos $\geq 1: 256$ eram mais elevadas em algumas aldeias, onde hábitos alimentares eram mais variados, semelhantes a populações não-índias, do que nas aldeias cuja fonte de proteína animal era predominantemente o peixe ${ }^{14}$. No entanto, no presente estudo, o grupo dos Enawenê-Nawê, que não se alimentava de carne vermelha, apresentou alta freqüência de títulos $\geq 1: 256(37,7 \%)$.

$\mathrm{Na}$ população estudada não se observaram diferenças estatisticamente significativas entre os indivíduos dos sexos feminino e masculino, pelas técnicas de ELISA ou IFI (Tabela 1). Estes resultados, com relação à diferença entre os sexos, são similares aos apresentados em outros trabalhos. Em índios do Alto Xingu, observou-se que $46,9 \%$ das reações eram positivas entre homens e $56,5 \%$ entre mulheres ${ }^{4}$. No Amapá, verificou-se $71,2 \%$ de reações positivas nos homens e $66,5 \%$ em mulheres ${ }^{8}$. Estes dados sugerem que, na toxoplasmose, não há predominância de reações positivas em relação ao sexo e as diferenças eventualmente registradas não são importantes, o que sugere que, embora as atividades dos indivíduos Enawenê-Nawê de sexos diferentes sejam bem distintas, a maioria esteve em contato com fatores 
de exposição se não na mesma intensidade, pelo menos com muita freqüência.

Quando se analisaram as reações positivas de acordo com os títulos da IFI, observou-se que os títulos de $\leq$ 1:256 foram os mais freqüentemente observados, sendo que $40,6 \%$ da população apresentaram títulos de 1:64. Estes dados são semelhantes aos encontrados em indígenas do Alto Xingu, onde $51,1 \%$ dos resultados obtidos pela IFI apresentaram títulos que variavam de $1: 16$ a $1: 256^{4}$. Nenhum caso sugestivo de infecção recente foi constatado pela pesquisa de anticorpos IgM nos Enawenê-Nawê, mostrando que, provavelmente, a infecção crônica por T. gondii prevalecia nesta população, pois a toxoplasmose é considerada uma zoonose endêmica autóctone ${ }^{6}$.

Correlacionando-se faixa etária com a soropositividade, tanto com ELISA quanto com IFI, observou-se que, nos Enawenê-Nawê, já a partir da terceira década de vida, ocorreu praticamente uma estabilização na freqüência da soropositividade (Tabela 1). Isto corrobora o fato de que há aumento da freqüência da infecção toxoplásmica com o aumento da faixa etária ${ }^{12}{ }^{20}$. Portanto, quanto maior a idade, maior a probabilidade do indivíduo entrar em contato com pelo menos um dos diversos mecanismos de transmissão considerados cumulativos ${ }^{123}$.

No caso dos Enawenê-Nawê, os indivíduos ficam mais expostos conforme começam a participar das atividades do grupo, principalmente à procura de alimento. O encontro de valores elevados de ocorrência da protozoose em faixas etárias de jovens, nesta população, sugere que mesmo as crianças já tiveram contato com os fatores de exposição à infecção, uma vez que $50 \%$ delas, com menos de 10 anos, foram soropositivas com ELISA ou IFI, e quatro tinham títulos IgG-IFI $\geq 1: 64$.

Sugere-se que os Enawenê-Nawê estão em contato com alguma fonte de infecção responsável pelo aumento na ocorrência de soropositivos para Toxoplasma gondii. Os Enawenê-Nawê apresentam uma dieta alimentar diferenciada, principalmente quanto à ingestão de fungos in natura localizados nas matas ciliares, com grande quantidade de matéria orgânica. Estes locais provavelmente devam ser visitados por felídeos silvestres à procura de água. Assim, estes felídeos podem contaminar estes ambientes com oocistos eliminados nas suas fezes. Possivelmente, este seria o fator que explicaria a elevada exposição ao T. gondii no grupo dos Enawenê-Nawê.

\section{AGRADECIMENTOS}

Agradecemos à Operação Amazônia Nativa (OPAN) pelo fornecimento dos dados epidemiológicos, a Regiane Trigueiro Vicente pelo amparo técnico e ao CNPq pelo apoio financeiro.

\section{REFERÊNCIAS BIBLIOGRÁFICAS}

1. Amendoeira MRR. Mecanismos de transmissão da toxoplasmose. Anais da Academia Nacional de Medicina. 155:224-225, 1995.

2. Amendoeira MRR, Costa T, Spalding SM. Toxoplasma gondii. In: Nicolle \& Manceaux (eds), 1909 (Apicomplexa: Sarcocystidae) e a Toxoplasmose. Revista Souza Marques 1: 15-35, 1999.

3. Apt W, Thiermann E, Niedmann G, Pasmanik S. Toxoplasmosis, Universidad de Chile, Santiago, Chile, 1973.

4. Baruzzi RG. Contribution to the study of the toxoplasmosis epidemiology. Serologic survey among the Indians of the Upper Xingu River, Central Brazil. Revista do Instituto de Medicina Tropical de São Paulo 12:93-104, 1970.

5. Camargo ME, Leser PG, Leser WSP. Diagnostic information from serological tests in human toxoplasmosis: Evolutive study of antibodies and serological patterns in acquired toxoplasmosis is detected by hemagglutination, complement fixation. IgG and IgM immunofluorescence tests. Revista do Instituto de Medicina Tropical de São Paulo 18:215-226, 1976.

6. Coimbra Júnior CEA, Santos RV. Paleoepidemiologia e epidemiologia de populações indígenas brasileiras: possibilidades de aproximação. In: Araújo AJG, Ferreira LF (eds) Paleopatologia \& Paleoepidemiologia: Estudos Multidisciplinares. Editora Panorama, Escola Nacional de Saúde Pública, Rio de Janeiro, p. 169-184, 1992.

7. Contreras M, Schenone H, Salinas P, Sandoval L, Rojas A, Villarroel F, Solis F. Seroepidemiology of human toxoplasmosis in Chile. Revista do Instituto de Medicina Tropical de São Paulo 38: 431-451, 1996.

8. Deane L. Inquérito de toxoplasmose e de tripanossomíases realizado no território do Amapá pela III Bandeira Científica do Centro Acadêmico "Oswaldo Cruz" FMUSP Revista Médica de São Paulo 47: 1-12, 1963.

9. Ferraroni JJ, Lacaz CS. Prevalência de anticorpos contra os agentes causadores da hepatite, malária, sífilis e toxoplasmose em cinco populações. Revista do Instituto de Medicina Tropical de São Paulo 24:155-161, 1982.

10. Ferraroni JJ, Marzochi MCA. Prevalência da infecção pelo Toxoplasma gondii em animais domésticos, silvestres e grupamentos humanos da Amazônia. Memórias do Instituto Oswaldo Cruz 75: 99-109, 1980.

11. Frenkel JK, Dubey JP. Toxoplasmosis and its prevention in cats and man. Journal of Infections Disease 126: 664-673, 1972.

12. Jamra LMF. Contribuição para a epidemiologia de toxoplasmose. Inquérito em 100 famílias de uma área da cidade de São Paulo. Tese de Doutorado, Faculdade de Medicina da Universidade de São Paulo, São Paulo, SP, 1964.

13. Leser PG, Camargo ME, Baruzzi R. Toxoplasmosis serologic tests in Brazilian Indians (kren-akore) of recent contact with civilized man. Revista do Instituto de Medicina Tropical de São Paulo 19: 232-236, 1977.

14. Lovelace JK, Moraes MAP, Hagerby E. Toxoplasmosis among the Ticuna Indians in the state of Amazonas, Brazil. Tropical and Geographical Medicine 30: 295-300, 1977. 
15. Neel JV, Andrade AHP, Brown GE, Eveland WE, Goobar J, Sodeman Jr WA, Stollerman GH, Weistein ED, Wheeler AH. Further studies of the Xavante Indians. American Journal Tropical Medicine and Hygiene 17: 486-498, 1968.

16. Operação Anchieta. Estudo das potencialidades e do manejo dos recursos naturais na área indígena Enawenê-Nawê. Relatório da Operação Anchieta. Centro de pesquisas do Pantanal, Amazônia e Cerrado. Universidade Federal do Mato Grosso, 1995.

17. Ricardo CA. Povos indígenas no Brasil, Instituto Sócio Ambiental, São Paulo, Brasil, 2000.

18. Rocha MO, Carvalho MG, Silva MBS, Lignani, C. Remanescentes Xakriabá em Minas Gerais: Prevalência da doença de Chagas e toxoplasmose e avaliação do quadro hematológico dos infectados. Revista de Farmácia e Bioquímica da Universidade Federal de Minas Gerais, Belo Horizonte 8:1927,1987
19. Rosa M, Bolivar J, Perez HA. Infeccion por Toxoplasma gondii en amerindios de la selva amazonica de Venezuela. Medicina (Buenos Aires) 59: 759-762, 1999.

20. Sánchez RM, Hernandez MS, Carvajales AF. Aspectos soroepidemiológicos de la toxoplasmosis en 2 municípios de la Provincia de Ciego de Avila. Revista Cubana de Medicina Tropical 41: 214 - 225, 1989.

21. Stata Corp. Stata Statistical Software: Release 7. College Station, Texas, 2002.

22. Uchôa CMA, Duarte R, Laurentino-Silva V, Alexandre GMC, Ferreira HG. Padronização de ensaio imunoenzimático para pesquisa de anticorpos das calasses IgM e IgG anti-Toxoplasma gondii e comparação com a técnica de imunofluorescência indireta. Revista da. Sociedade Brasileira de Medicina Tropical 32: 661-669, 1999.

23. Wallace GD, Zigas V, Gajdusek DC. Toxoplasmosis and cats in New Guinea. American Journal of Tropical Medicine and Hygiene 23: 813, 1974. 